Vol 14, Issue 10, 2021

\title{
FORMULATION AND EVALUATION OF ANTIFUNGAL NANOGEL FOR TOPICAL DRUG DELIVERY SYSTEM
}

\author{
ANASUYA PATIL*, PRANOTI KONTAMWAR \\ Department of Pharmaceutics, KLE College of Pharmacy, II Block Rajajinagar, Bengaluru, Karnataka, India. \\ Email: anusuya_k_p@yahoo.co.in
}

Received: 02 May 2021, Revised and Accepted: 10 September 2021

\section{ABSTRACT}

Objectives: Ciclopirox olamine has been employed as an antifungal agent. An oral route of administration of Ciclopiroxa olamine causes irritation and ulceration of GIT because of this it is used in the form of topical formulation. In this research work, antifungal nanogel formulated to reduce size of particle, improve in-vitro release and in-vivo release study.

Methods: Ciclopirox olamine nanogels were prepared using homogenization technique and incorporation of Carbopol 940 as a gelling agent in producing a smooth antifungal nanogel (F1-F6).

Results: Antigungal Nanogels (F1-F6) were subjected to Fourier transform infrared study and showed no interaction between the drug and excipients. The best formulation (F6) elicited the high in-vitro release of $83.42 \%$ at $8 \mathrm{~h}$; zeta-potential and particle size, obtained values were - $27 \mathrm{mV}$ and $230 \mathrm{~nm}$ correspondingly. In-vitro release kinetic models were shown that formulation-F6 follows First-order kinetics and high regression coefficient value $r^{2}$ 0.9866. Scanning electron microscope image of the best formulation-F6 depicts that no breakage of nanogel. The differential scanning calorimetry (DSC) thermogram of ciclopirox olamine was found to be $140.09 .7^{\circ} \mathrm{C}$. The DSC thermogram of physical mixture of carbopol 940 and Euragit-S 100 was found to be $129^{\circ} \mathrm{C}$ and $218^{\circ} \mathrm{C}$. DSC study of nanogel (F6) showed no interaction between drug and excipients. The best formulation-F6 was subjected to in-vivo study on mice which showed better effect in treating dermatitis.

Conclusion: It would be concluded that the best formulation-F6 which elicited better in-vitro drug release and enhanced dermatitis scoring.

Keywords: Ciclopirox-olamine, Eudragit-S100, Glycerol, Dermatitis, Carbopol-940, Cellophane membrane.

(C) 2021 The Authors. Published by Innovare Academic Sciences Pvt Ltd. This is an open access article under the CC BY license (http://creativecommons.org/ licenses/by/4.0/) DOI: http://dx.doi.org/10.22159/ajpcr.2021v14i10.42421. Journal homepage: https://innovareacademics.in/journals/index.php/ajpcr

\section{INTRODUCTION}

The most common skin problem is fungal infection caused by Trichophyton rubrum and Trichophyton mentagrophytes which are present in the environment. Fungi live on indoor surfaces and an outdoor in soil, on human skin and become extra complex in diabetes patient. A fungal infection characterized by red rashes and repeatedly substantial itching. Physicians prescribe a variety of medicines which are liquid to semi-solid and solid dosage forms. Most treatments require long-term oral dose of 3-9 months. The long-term use of oral medicines would increase the chances of side effect. Therefore, it is better to focus on topical drug delivery to reduce the duration of treatment. Out of the treatments, the most commonly used is topical preparations [1].

\section{Ring worm of the body}

Ringworm is caused by fungus and not a warm. It occurs typically on the torso and limbs. Ringworm on other areas of the body can have different names such as athlete's foot and jock itch. The main symptom of ringworm is a ring-shaped rash and slightly raised edges. The skin inside these circular rashes usually looks healthy. The rash can spread and its often itchy. Ringworm is common fungal infection and highly contagious. It can usually be treated with topical formulations. Cutaneous candidiasis is a skin infection caused by candida fungi. This type of fungi is naturally present on and inside our bodies. When it overgrows, an infection can happen. Candida skin infections occur in areas that that are warm, moist and poorly ventilated. Some examples that can be affected include under the breasts and in the folds of the buttocks, such as in diaper rash. Onychomycosis is a fungal infection of your nails. It can affect the finger nails or the toe nails, although infections of the toe nails are common.
New therapy of nanotechnology and an increased understanding of fungal infection have brought us closer to the goal of being safe and efficacious for the treatment of fungal skin diseases [4]. Nanotechnology has potential applications in the administration of healing agents and in analytic procedures. The nano-particulates drug delivery system offers plenty of advantages over conventional dosage forms for example reduced toxicity, enhanced bio-distribution and improved patient compliance.

The necessity for evolving topical novel drug delivery systems using nanotechnology is rising day by day. Nanogels are highly biocompatible, biodegradable, good transport characteristics, and good permeation capabilities. The pharmaceutical manufacturing companies are concentrating on the expansion of the innovative system to deliver drugs with the view to improve their efficacy.

Ciclopirox olamine which belongs to an anti-fungal category used to treat superficial mycoses. Therefore, in the current research work ciclopirox olamine was chosen as an ideal drug molecule for topical preparation. The aim of the research work was to formulate and evaluate an antifungal nanogel to enhance in-vitro release and to reduce the dosing frequency.

\section{MATERIALS AND METHODS}

\section{Materials}

Ciclopirox olamine procured from Yarrow chemicals Research Pvt. Ltd, Mumbai. Cabopol-940 received from SDFC Pvt. Ltd. Eudragit RS100 purchased from Yarrow chem. Pvt. Ltd. Tween-80, potassium di-hydrogen phosphate, and sodium hydroxide obtained from Sisco laboratories Pvt. Ltd. Glycerol ordered from HiMedia Lab Pvt. Ltd. All other raw materials used are pharmaceutical grade. 


\section{Methodology}

Pre-formulation studies

Estimation of $\lambda_{\max }$ of Ciclopirox olamine: The solution containing concentration of $10 \mu \mathrm{g} / \mathrm{ml}$ ciclopirox olamine was prepared and scanned over the wavelength $200-400 \mathrm{~nm}$ using Ultraviolet (UV)1700 spectrometer, Shimadzu Co., JPN to estimate the wavelength of maximum absorbance [1].

\section{Estimation of melting point}

A small amount of ciclopirox olamine was introduced into the capillary tube and the capillary tube was attached to the twig of thermometer. Thermometer was placed into Thiele's tube containing liquid paraffin [2]. Side support of the Thiele's tube was heated and the temperature was observed at which melting of drug begins and complete.

\section{Determination of saturation solubility of ciclopirox olamine}

The saturation solubility was conducted using four different solvents such as methanol, ethanol, water, and phosphate buffer $\mathrm{pH} 7.4$. Increments of ciclopirox olamine were added to each solvent and sonicated for $30 \mathrm{~min}$ until it reaches saturation. The saturated solution was centrifuged for $5 \mathrm{~min}$ and the aliquots supernatant solution were taken and diluted to $10 \mathrm{ml}$ with the same solvents and subjected to UVquantification using UV-1700 spectrometer, Shimadzu Co., JPN.

\section{Compatibility studies}

To check compatibility of ciclopirox olamine along with polymer using Fourier transform infrared (FT-IR) were performed [3].

\section{Standard curve of ciclopirox olamine}

Ciclopirox-olamine was exactly weighed and dissolved to get concentration as the primary solution. $1 \mathrm{ml}$ of the primary solution was taken to $10 \mathrm{ml}$ volumetric flask to get as secondary stock solution [5]. $0.2-1 \mathrm{ml}$ was taken from secondary stock solution to $10 \mathrm{ml}$ volumetric flask and diluted using phosphate buffer $\mathrm{pH} 7.4$ to get concentration $2-10 \mu \mathrm{g} / \mathrm{ml}$ and measured using UV-1700 spectrometer, Shimadzu Co. JPN.

\section{Formulation of ciclopirox-olamine nanogel}

Accurately weighed quantity of ciclopirox-olamine, Eudragit S-100 and Tween- 80 as stabilizer were dissolved in glycerol with stirring and aqueous phase prepared using Carbopol-940 dissolved in water with continuous stirring and heat $[3,6]$. The drug containing phase was sonicated on Ultra-sonicator (Make of the equipment-Wemsan). The drug phase was added drop by drop into an aqueous phase with continous stirring to get a uniform emulsion (o/w emulsion) which was converted into nano-droplets using homogenizer (Make-Remi-motors). Homogenization was continued for $1 \mathrm{~h}$ at $8000 \mathrm{rpm}$. Triethanolamine was added to form nanogel. Prepared Ciclopirox-olamine nanogels were subjected to various tests.

\section{Evaluation of ciclopirox-olamine nanogel}

Ciclopirox-olamine nanogels were evaluated for these parameters: Physical appearance, determination of $\mathrm{pH}$, estimation of practical yield, determination of homogeneity, estimation of drug content uniformity, determination of spreadability, determination of viscosity, Statistical analysis of experimental data by ANOVA using Excel, In-vitro-drug release study, release kinetic study, Particle size analysis, estimation of Zeta potential, differential scanning colorimetry (DSC), Scanning electron microscopy (SEM), In-vitro release data further subjected to statistical analysis using One-way ANOVA by GraphPad Prism5, FT-IR studies and anti-fungal activity of nanogel.

\section{Physical appearance}

One of the important characteristic features of nanogel formulations is clarity of the formulation [2,7]. The prepared anti-fungal nanogels were evaluated for clarity by visual checking against a black and white texture.

\section{Measurement of $p H$}

The formulated antifungal nanogels were measured $\mathrm{pH}$ using digital $\mathrm{pH}$ meter and make of the equipment-Digisun Electronics services [3].

Determination of practical yield

Percentage of practical yield calculated using the following formula.

$\%$ yield $=$ the experimental yield divided by theoretical yield multiplied by 100 .

\section{Determination of homogeneity}

Homogeneity by visual examination done for all developed nanogel has remained to set in the beaker $[3,8]$. Nanogels were tested for physical properties and presence of any particle.

\section{Estimation of drug content uniformity}

The estimation of drug in nanogel was carried out by employing $1 \mathrm{gm}$ of nanogel mixed with $50 \mathrm{ml}$ of phosphate buffer $\mathrm{pH} 7.4$ and membrane filter was used to filter obtained mixture. From this mixture, $2 \mathrm{ml}$ of sample was pipette out and made up to $10 \mathrm{ml}$ sample was analyzed for its absorbance spectrophotometrically at $222 \mathrm{~nm}[3,9]$. The concentration of the ciclopirox-olamine in the test sample was estimated from the calibration curve.

\section{Determination of Nangogel spreadability}

A test sample of $1 \mathrm{gm}$ of nanogel was placed in the two glass slides and $1 \mathrm{~kg}$ weight was placed on the slide for $10 \mathrm{~min}$ to obtain a consistent thickness and spreadability of a test sample [3]. The spreadability of the test sample nanogel was measured within minute by keeping two slides.

\section{Statistical data analysis using excel-sheet}

The spreadability experimental data was subjected to statistical analysis using One-way ANOVA.

\section{Measurement of viscosity of anti-fungal nanogel}

Nanogels viscosity was measured using Brookfield viscometer (Dv-E, Brookfield). In this method, the spindle number-4 was almost touched the surface of nanogel $[5,11,12]$. Brookfield viscometer dial readings were noted at different rpm and viscosity was measured.

\section{In-vitro release study}

The in-vitro release of drug was performed for nanogel formulations (F1-F6) and standard drug. Franz diffusion cell (Make-Orchid scientific) containing cellophane dialysis membrane was used. The donor compartment was loaded with $1 \mathrm{gm}$ of nanogel soaked in phosphate buffer $\mathrm{pH} 7.4$ solutions at room temperature under slow magnetic stirring $[1,14,15]$. At regular time intervals, $1 \mathrm{ml}$ of aliquot was withdrawn from receptor chamber through the sampling port and immediately replaced with fresh buffer solution of same volume. Aliquot was diluted and the amount of drug released was determined using UV- spectrophotometer at $222 \mathrm{~nm}$.

\section{In-vitro release kinetic study}

According to the principle of pharmacokinetics, the drug release kinetic for dosage form can be represented by various equations followed by various kinetic models $[6,16,18]$.

\section{Measurement of particle size and zeta potential}

The mean size and Zeta potential of the best nanogel formulation (F6) was measured by using Horiba sizer.

DSC

DSC studies of the best formulation (F6) were performed using equipment DSC 60; Shimadzu. DSC thermogram showed that a sharp 
endothermic peak at $140.49^{\circ} \mathrm{C}$ which matches with the melting point of ciclopirox olamine indicating that the drug purity. From the DSC overlay thermogram of pure drug-ciclopirox olamine and Eudragit-S 100 , it could be stated that no interaction between drug and excipients. Moreover, it also depicts that drug did not form a complex with excipients.

EMSEM analysis was performed using Imina applying a beam of electrons (having high-energy) in the range of 10,000 electron volts and the magnification power $600 \times[5,19,20]$.

\section{FT-IR study}

FT-IR antifungal nanogels were performed to check the interaction between ciclopirox olamine and polymer [5]. The FT-IR spectrum of nanogel was carried out by FT-IR JASCO 460 Plus shows that there is no interaction between excipient/ciclopirox olamine.

Table 1: Reported and observed frequencies FT-IR functional group range of ciclopirox olamine

Sl. Functional Reported-frequencies Observed-frequencies-

\begin{tabular}{llll} 
no. & group & $\mathbf{( \mathbf { c m } ^ { 1 } )}$ & $\mathbf{( \mathbf { c m } ^ { - 1 } ) .}$ \\
\hline 1 & $\mathrm{O}-\mathrm{H}$ & 1644 or $1646\left(\mathrm{~cm}^{-1}\right)$ & $1629.5\left(\mathrm{~cm}^{-1}\right)$ \\
2 & $\mathrm{C}=0$ & $1700\left(\mathrm{~cm}^{-1}\right)$ & $1554.5\left(\mathrm{~cm}^{-1}\right)$ \\
3 & $\mathrm{~N}-\mathrm{H}$ & $3400\left(\mathrm{~cm}^{-1}\right)$ & $3214.7\left(\mathrm{~cm}^{-1}\right)$ \\
4 & C-O & $1100\left(\mathrm{~cm}^{-1}\right)$ & $1165.767\left(\mathrm{~cm}^{-1}\right)$ \\
\hline
\end{tabular}

Table 2: Reported and observed FT-IR frequencies of ciclopirox olamine nanogel Formulation (F6)

\begin{tabular}{llll}
\hline $\begin{array}{l}\text { Sl. } \\
\text { no. }\end{array}$ & $\begin{array}{l}\text { Functional } \\
\text { groups }\end{array}$ & $\begin{array}{l}\text { observed } \\
\text { peak }\left(\mathbf{c m}^{-1}\right)\end{array}$ & $\begin{array}{l}\text { Standard } \\
\text { peak }\left(\mathbf{c m}^{-1}\right)\end{array}$ \\
\hline 1 & N-H & 3305.96 & 3340 \\
2 & O-H & 1635.86 & 1635.86 \\
3 & C-N & 1112.45 & 1100 \\
4 & C=O & 1024.56 & 1000 \\
\hline
\end{tabular}

Statistical data analysis using GraphPad Prism5

Statistical in-vitro data analysis was performed using GraphPad Prism5 by One-way ANOVA $[6,21]$.

\section{In-vivo studies of antifungal nanogel}

Material and Method: Animal species: Balb/c mice, Sex: Female, Age: Adult, Test sample: Ciclopirox Olamine, Dose: Quantity sufficient for the affected area, Inducing agent: Imiquimod (IMQ), dose $3.124 \mathrm{mg} / \mathrm{animal}$, Route of administration: Topical, Duration: 1 week after the induction.

Treatment protocol: The IMQ was applied on the shaved back of the balb/c mice. $62.5 \mathrm{mg}$ of nangogel or $3.124 \mathrm{mg}$ of the active component was applied daily. The treatment was started from the $8^{\text {th }}$ day onwards and continued for 1 week [5,22]. Both the formulations were applied on the affected area of the skin and allowed it to absorb into the skin. After 1 -week treatment, the scoring was observed to evaluate the dermatitis.

\section{RESULTS AND DISCUSSION}

\section{Per-formulation studies}

Standard curve of ciclopirox olamine

$\lambda_{\max }$ of ciclopirox olamine in phosphate buffer $\mathrm{pH} 7.4$ showed the maximum absorbance at $222 \mathrm{~nm}$ that is similar to the reported value. Ciclopirox olamine concentration in each sample was analyzed using UV- spectrophotometer at $222 \mathrm{~nm}$. The calibration curve of ciclopirox olamine was linear over a concentration range $2-10 \mu \mathrm{g} / \mathrm{ml}$ and regression value $\mathrm{r}^{2}=0.997$ (Figs. 6 and 7).

\section{Determination of melting-point}

The melting-point of ciclopirox olamine was found to be $143^{\circ} \mathrm{C}$ as reported in literature.

\section{Saturation solubility studies}

The saturation solubility of ciclopirox olamine was estimated in various solvents. Solubility of ciclopirox olamine in ethanol, water, and phosphate buffer 7.4 was found to be $1.28 \mathrm{mg} / \mathrm{ml}, 100 \mathrm{mg} / \mathrm{ml}$, and $78 \mathrm{mg} / \mathrm{ml}$ respectively.

Table 3: A various assessment parameters for ciclopirox olamine nanogel

\begin{tabular}{llllllll}
\hline Formulations & Physical appearance & pH & \% Yield & Homogeneity & Drug content & Spread ability & Viscosity (cps) \\
\hline F1 & Clear & 6.5 & $72 \%$ & Homogeneous & $76 \%$ & $6.9 \mathrm{~cm}$ & 8561 \\
F2 & Clear & 6.8 & $77 \%$ & Homogeneous & $75 \%$ & $7.4 \mathrm{~cm}$ & 8791 \\
F3 & Clear & 6.6 & $80 \%$ & Homogeneous & $68 \%$ & $7.3 \mathrm{~cm}$ & 9857 \\
F4 & Clear & 6.7 & $70 \%$ & Homogeneous & $71 \%$ & $7.6 \mathrm{~cm}$ & 9766 \\
F5 & Clear & 6.2 & $79 \%$ & Homogeneous & $73 \%$ & $6.3 \mathrm{~cm}$ & 9453 \\
F6 & Clear & 6.9 & $82 \%$ & Homogeneous & $80 \%$ & $7.9 \mathrm{~cm}$ & 9666 \\
\hline
\end{tabular}

All values are expressed as mean, $n=3$

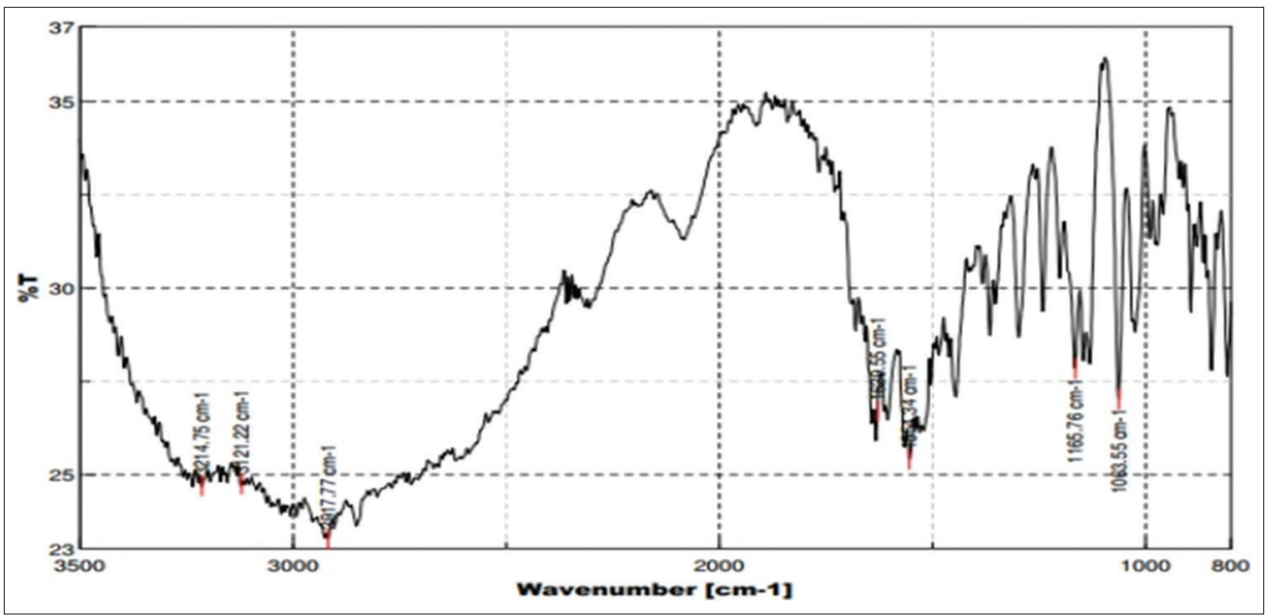

Fig. 1: Fourier transform infrared spectrum of ciclopirox olamine 


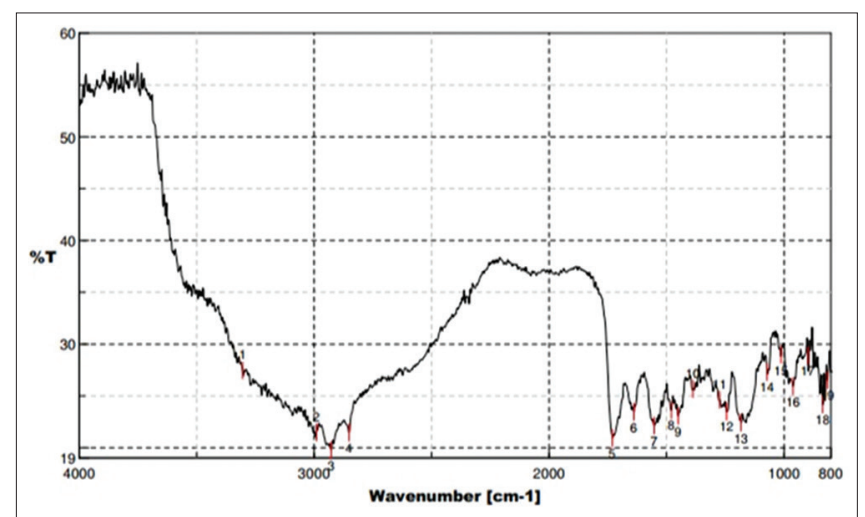

Fig. 2: Fourier transform infrared spectrum of Eudragit- S-100

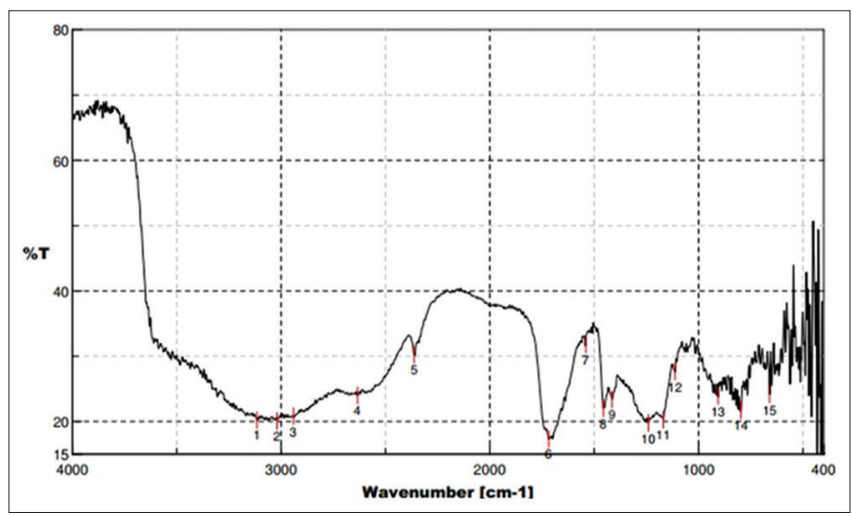

Fig. 3: Fourier transform infrared Spectrum of Carbopol-940

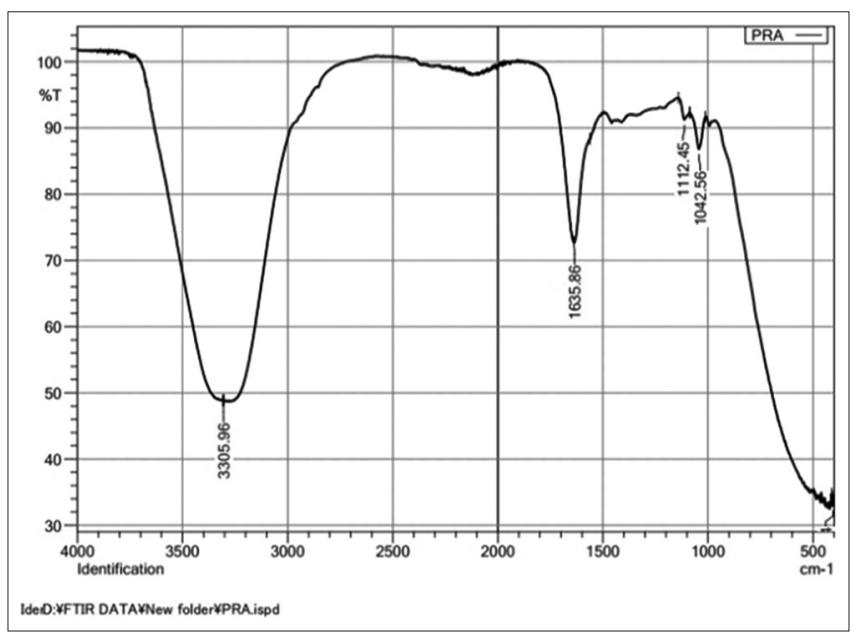

Fig. 4: Infrared spectrum of nanogel formulation (F6)
FT-IR analysis

Ciclopirox olamine pure drug, polymer Eudragit S-100 and physical mixture of ciclopirox olamine and Eudragit S 100 recorded using FT-IR spectroscopy.

The FT-IR spectrum of ciclopirox olamine ando excipients were recorded using FT-IR spectrophotometer and were compared with standard functional frequencies and excipient physical mixture showed characteristic peaks of the drug due to $\mathrm{C}-\mathrm{N}, \mathrm{O}-\mathrm{H}$ and $\mathrm{N}-\mathrm{H}$, $\mathrm{C}=0$ appeared at their respective wave numbers 1112.45 , 1635.86, 3305.96, $1024.56 \mathrm{~cm}^{-1}$ ciclopirox olamine with no major shifts indicating compatibility of drug and excipients. FT-IR study was achieved and nearly showed same characteristic peaks of ciclopirox olamine indicating no interaction and would be depicted that ciclopirox olamine was completely compatible with Eudragit-S 100 used in the best formulation F6 (Figs. 2 and 3).

Evaluation of ciclopirox olamine nanogel

Prepared anti-fungal nanogels were subjected to various evaluation parameters like appearance, $\%$ yield, $\mathrm{pH}$, drug content, spreadability and viscosity. The spreadability of nanogel was found to be in range of $6.2-7.9 \mathrm{~cm}$. Viscosity range of nanogel was found to be 8516-9666 dyne $\mathrm{s} / \mathrm{cm}$.

Statistical analysis by one-way ANOVA using excel-sheet

Experimental data of antifungal nanogel was subjected to statistical analysis using One-way ANOVA.

Table 4: \% cumulative release of formulation (F1-F6) and pure drug

\begin{tabular}{lllllllc}
\hline $\begin{array}{l}\text { Time } \\
\text { (h) }\end{array}$ & $\begin{array}{l}\text { Ciclopirox } \\
\text { olamine }\end{array}$ & F1 & F2 & F3 & F4 & F5 & F6 \\
\hline 1 & 6.9 & 12.8 & 19.7 & 12.8 & 24.2 & 27.4 & 26.0 \\
2 & 14.6 & 18.0 & 28.0 & 19.7 & 36.0 & 36.0 & 38.2 \\
3 & 23.3 & 23.1 & 38.2 & 23.7 & 41.4 & 41.4 & 42.8 \\
4 & 35.5 & 28.0 & 41.1 & 38.0 & 48.2 & 47.4 & 51.1 \\
5 & 46.6 & 34.8 & 48.2 & 45.4 & 53.4 & 56.8 & 60.2 \\
6 & 56.1 & 41.7 & 50.2 & 47.4 & 56.5 & 60.8 & 70.2 \\
7 & 69.8 & 47.7 & 52.8 & 50.2 & 59.4 & 66.8 & 76.5 \\
8 & 71.2 & 52.2 & 53.7 & 55.7 & 63.71 & 73.0 & 83.4 \\
\hline
\end{tabular}

Table 5: Kinetic values obtained from in-vitro release of anti-fungal nanogel formulation-F6

\begin{tabular}{llll}
\hline $\begin{array}{l}\text { Kinetic } \\
\text { models }\end{array}$ & Slope (n) & Rate constant & $\begin{array}{l}\text { Regression } \\
\text { coefficient }\end{array}$ \\
\hline Zero order & 1.2867 & +3.2515 & 0.9902 \\
First order & 4.9999 & -1.1492 & 0.984 \\
Korsmeyer-Peppas & 0.5517 & -0.4671 & 0.9864 \\
Higuchi & 0.0675 & +1.3743 & 0.9496 \\
\hline
\end{tabular}

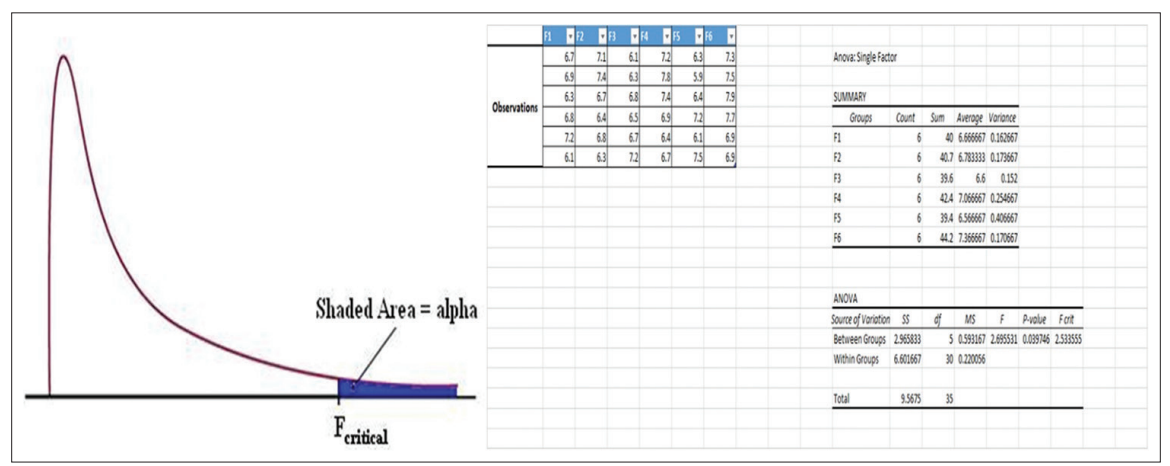

Fig. 5: Statistical analysis by one-way ANOVA using Excel sheet 
In-vitro release profile of ciclopirox olamine nanogel

Release data obtained from in-vitro release of nanogel formulations F1 to F6, pure drug-ciclopirox olamine using Phosphate buffer $\mathrm{pH} 7.4$ is shown in table and figure.

Table 6: Dermatitis severity scoring data

\begin{tabular}{|c|c|c|c|c|}
\hline Group & Animal No. & Erythema & Scaling & Thickening \\
\hline \multirow[t]{6}{*}{ IMQ control } & 1 & 3 & 3 & 4 \\
\hline & 2 & 4 & 2 & 3 \\
\hline & 3 & 3 & 2 & 3 \\
\hline & 4 & 4 & 3 & 3 \\
\hline & 5 & 4 & 2 & 3 \\
\hline & 6 & 3 & 2 & 4 \\
\hline Mean & & 3.5 & 2.3 & 3.3 \\
\hline SEM & & 0.2 & 0.2 & 0.2 \\
\hline Ciclopirox & 7 & 2 & 1 & 2 \\
\hline olamine & 8 & 3 & 2 & 2 \\
\hline Marketed & 9 & 3 & 1 & 3 \\
\hline \multirow[t]{3}{*}{ formulation } & 10 & 2 & 2 & 1 \\
\hline & 11 & 2 & 2 & 2 \\
\hline & 12 & 3 & 2 & 3 \\
\hline Mean & & 2.5 & 1.7 & 2.2 \\
\hline SEM & & 0.2 & 0.2 & 0.3 \\
\hline Ciclopirox & 13 & 1 & 2 & 2 \\
\hline olamine test & 14 & 2 & 1 & 2 \\
\hline \multirow{4}{*}{ sample } & 15 & 2 & 0 & 1 \\
\hline & 16 & 1 & 1 & 2 \\
\hline & 17 & 2 & 0 & 1 \\
\hline & 18 & 2 & 1 & 1 \\
\hline Mean & & 1.7 & 0.8 & 1.5 \\
\hline SEM & & 0.2 & 0.3 & 0.2 \\
\hline
\end{tabular}

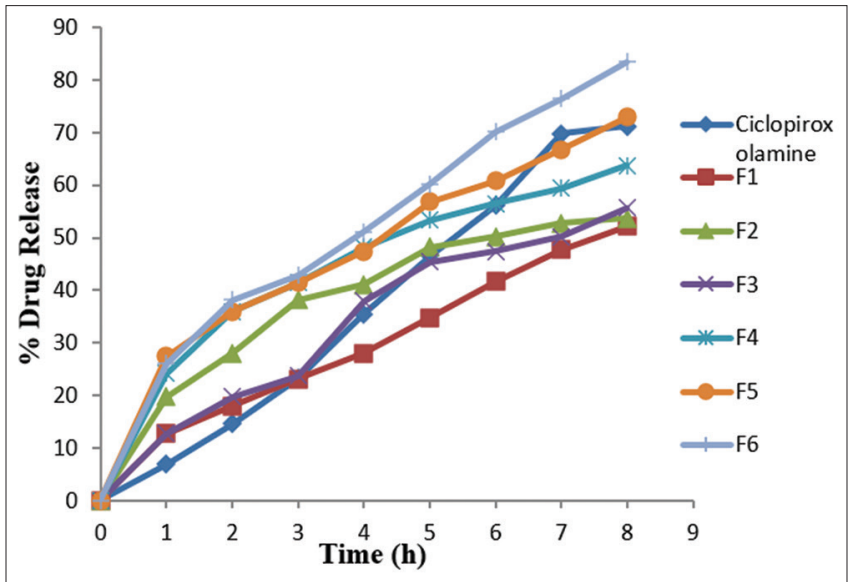

Fig. 6: In-vitro release profile of Ciclopirox olamine nanogel formulations F1- F6
In-vitro release studies at different ratios, ciclopirox olamine and Eudragit-S 100 performed at $8 \mathrm{~h}$ using Franz Diffusion Cell apparatus. The in-vitro release results of nanogels F1-F6 were compared with ciclopirox olamine. Nanogel of ciclopirox olamine Eudragit-S 100 and prepared using homogenization method showed drug release in formulations such as F1, F2, F3, F4, F5 and F6 were 52.28\%, $53.71 \%, 55.71 \%, 63.71 \% 73.14 \%$ 83.42\% respectively. Nangogel formulation-F6 elicited highest rate of drug release. In-vitro drug release profile of formulation-F6 was observed $83.42 \%$ release at $8 \mathrm{~h}$ (Fig. 6).

Zeta potential of nanogel formulation-F 6 was found to be $-27 \mathrm{mV}$ which indicated that particles prevent aggregation and hence stability of nanogel (F6) would be maintained. The mean particle size of nanogel nanogel formulation F6 was found to be $230 \mathrm{~nm}$.

\section{Release kinetics-models}

In-vitro release data was exposed to different kinetic models like Zero-order release kinetics model, First-order release kinetics model, Higuchi-diffusion release kinetic model and Peppa's kinetic model. The regression co-efficient ( $r$ ) and ' $n$ ' values of all the kinetic models are shown in table for nanogel formulation F6. Plots are shown in figure.

The higher degree of the co-rrelation co-efficient determines the suitable kinetic model that follows drug release kinetics from the above table; it was found that zero-order kinetics showed highest correlation coefficient than other kinetic models (Figs. 8-11)

Finalized nanogel formulation (F6) elicited highest in-vitro drug release $83.42 \%$ at $8 \mathrm{~h}$, particle size and Zeta potential observed $230 \mathrm{~nm}$ and $-27 \mathrm{mV}$, respectively, in-vitro release kinetic models for nanogel formulation-F6 was shown that it follows First-order kinetics and high regression coefficient value $\mathrm{r}^{2}=0.9866$.

\section{DSC analysis}

Ciclopirox olamine and the best formulations were subjected to DSC studies to know the dispersion of drug in polymer Eudragit-S 100. DSC study was performed using the instrument Perkin Elmer 4000. The DSC thermogram of ciclopirox olamine shows a sharp endotherm at $140.09^{\circ} \mathrm{C}$ which is near to the actual melting point of ciclopirox olamine. The ciclopirox olamine nanogel showed sharp endothermic peak at $218.08^{\circ} \mathrm{C}$ which is almost near to actual melting point of Eudragit-S 100. DSC thermogram of excipients showed the peak $129.4^{\circ} \mathrm{C}$ and the combined peak of Eudragit-S 100 was showed at $218.8^{\circ} \mathrm{C}$ (Figs. 13 and 14 )

SEM images of ciclopirox olamine nanogel shown in the figure. SEM photographs of ciclopirox olamine nanogel appeared as spherical shape (Fig. 15).

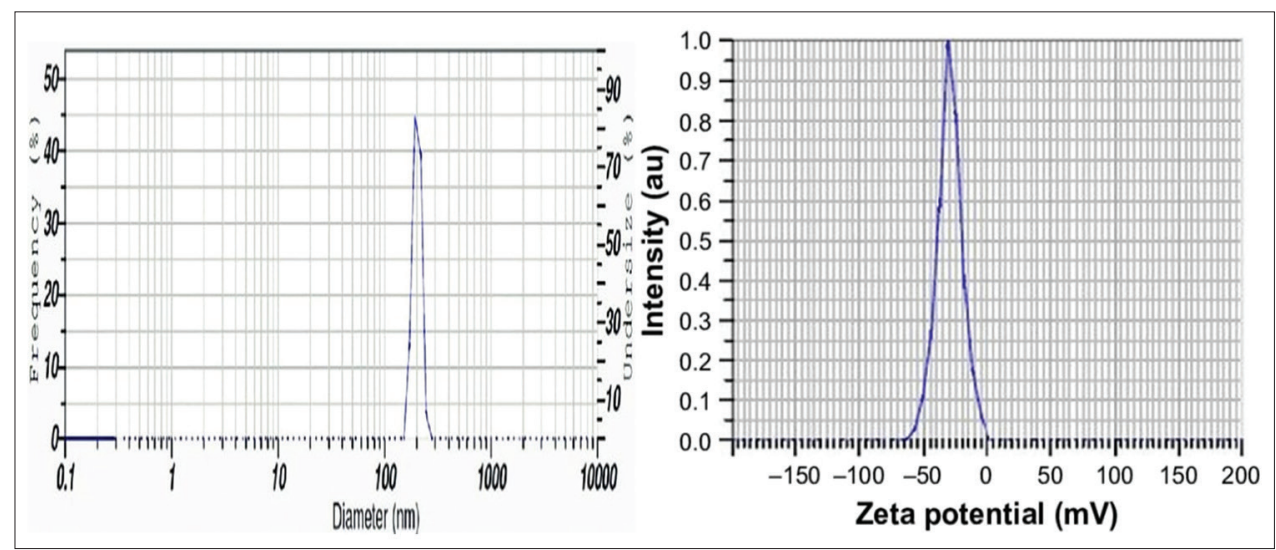

Fig. 7: Zeta potential and particle size 


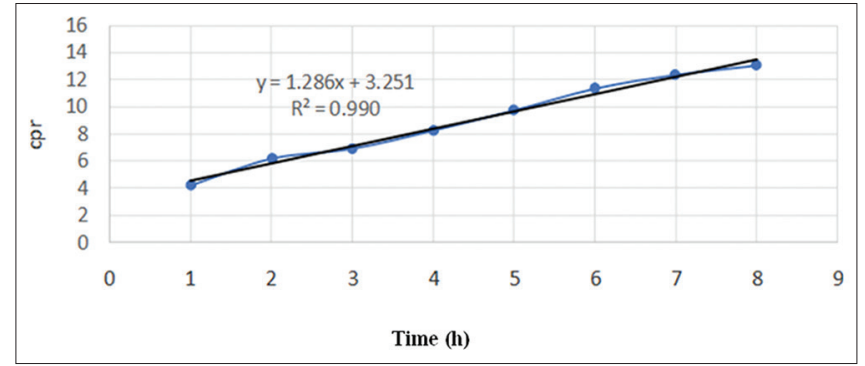

Fig. 8: Zero- order release-kinetic model

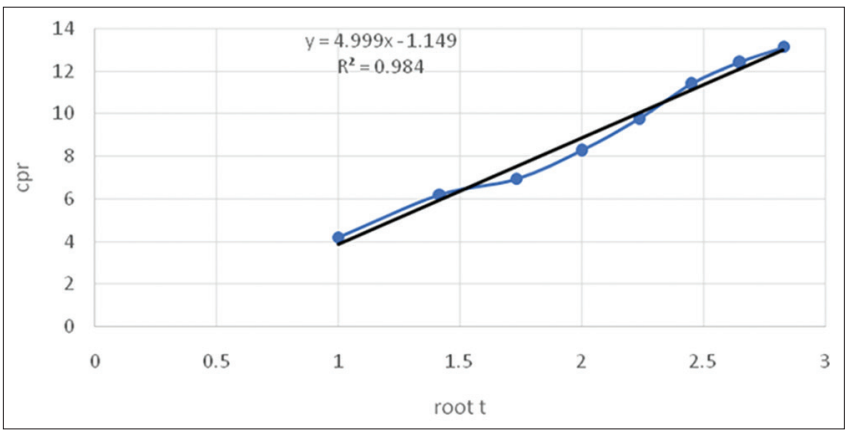

Fig. 9: First-order kinetic release model

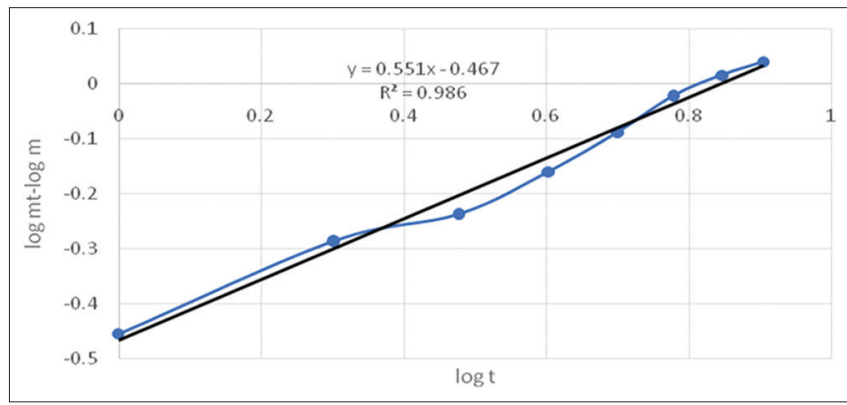

Fig. 10: Korsmeyer Peppa's kinetic model

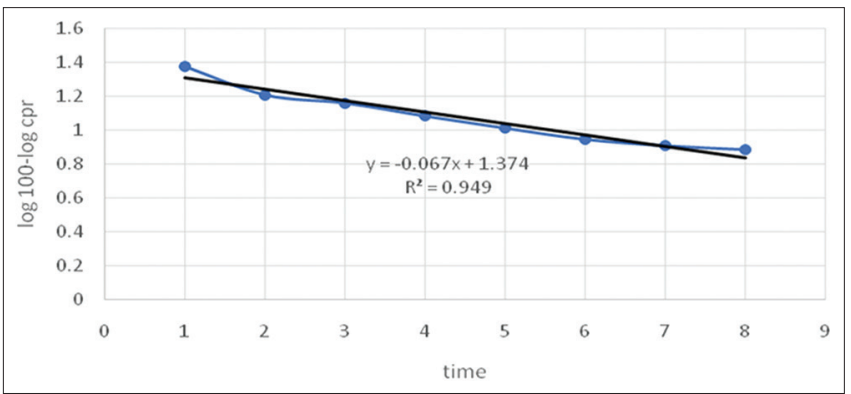

Fig. 11: Higuchi kinetic model

After the treatment period the dermatitis was scored based on erythema, scaling, and thickening were scored independently on a scale from 0 to 4 . Whereas 0 -none; 1 -slight; 2-moderate; 3 -marked, and 4-very marked (Figs. 16-19).

\section{SEM}

SEM of the nanogel (F6) performed using an instrument IMINA under the magnification of $600 \times$ and energy range 10,000 electron volts and it was observed that $250 \mathrm{~nm}$ size of the nanogel

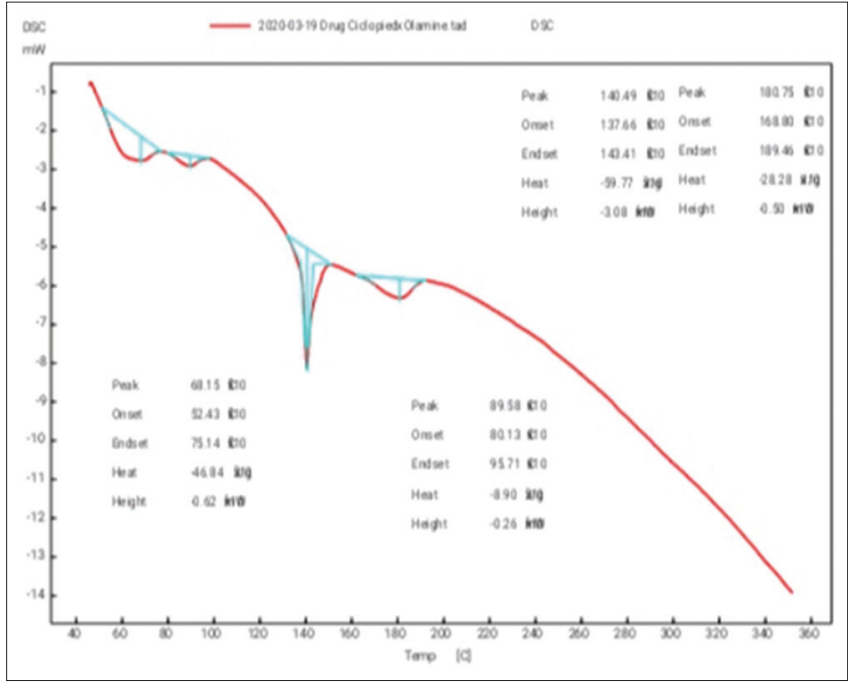

Fig. 12: Differential scanning calorimetry thermogram of ciclopirox olamine

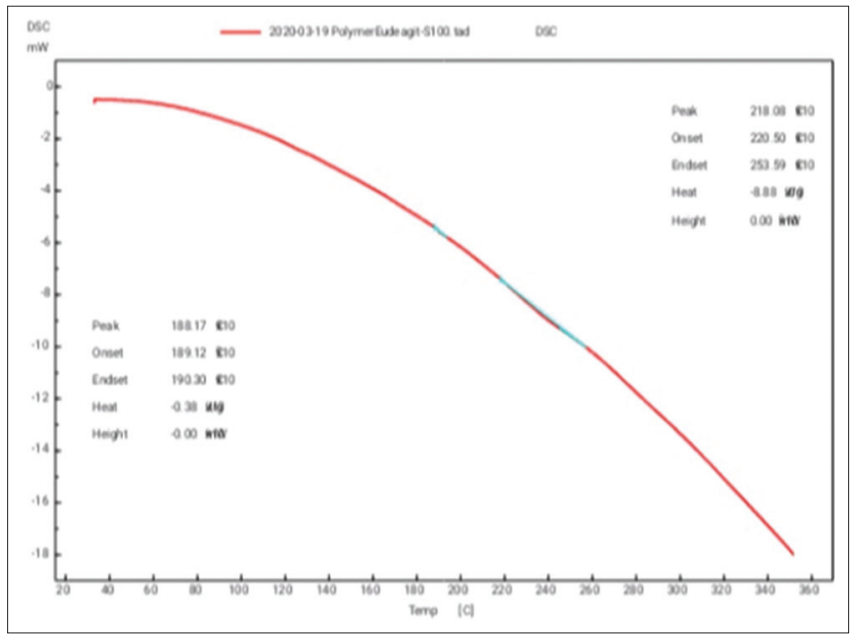

Fig. 13: Differential scanning calorimetry thermogram of Eudragit-S 100

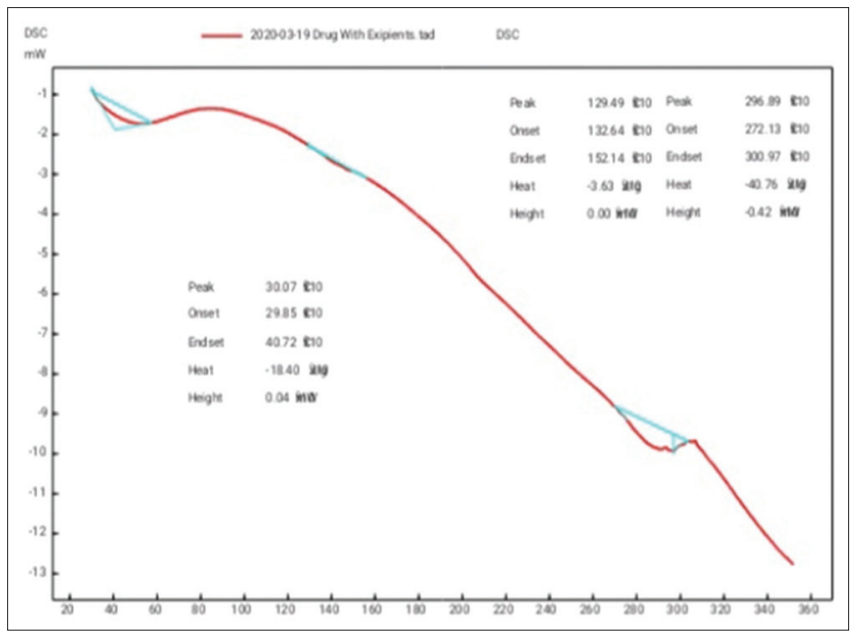

Fig. 14: Differential scanning calorimetry thermogram of drug ciclopirox olamine with Eudragit S-100 carbopol 940

formulation F6. SEM image shows that there is no breakage of nanogel (Fig. 15). 


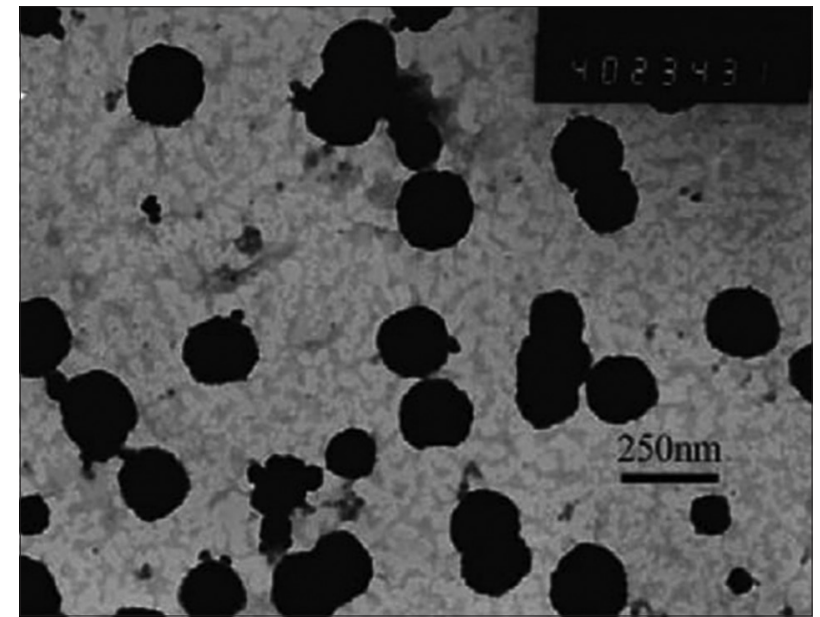

Fig. 15: Scanning electron microscopy of nanogel formulation (F6)

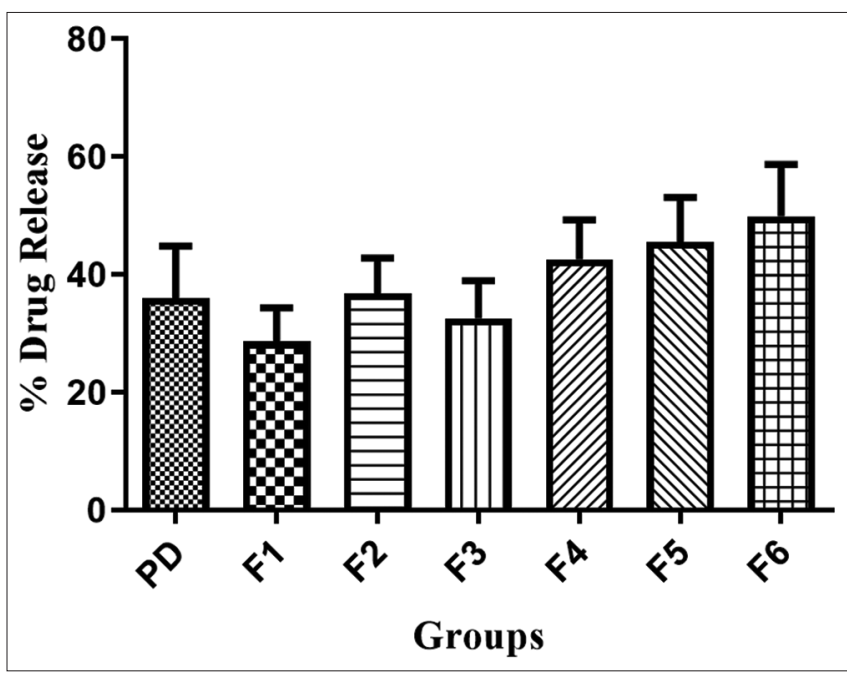

Fig. 16: Grouped data by Graphpad prism using one-way ANOVA

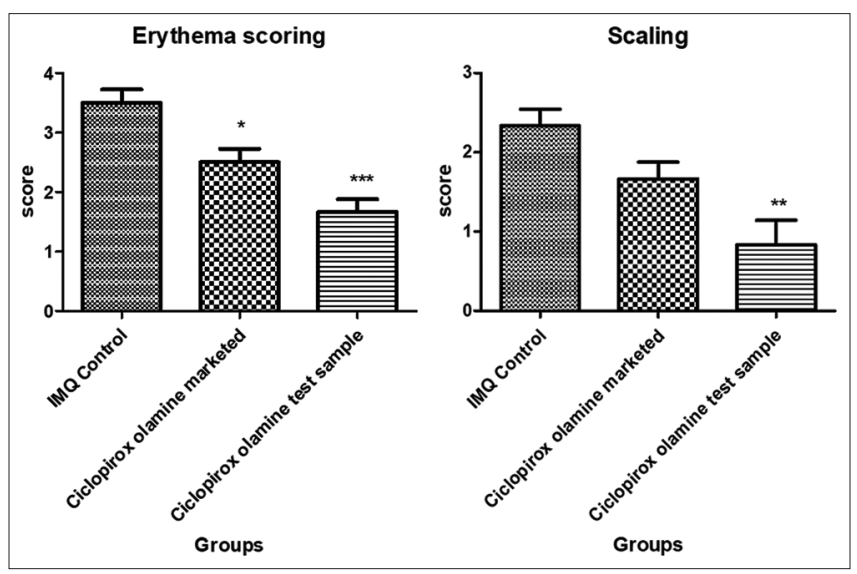

Fig. 17: Dermatitis characterized by scaling and erythema scoring

Statistical analysis using GraphPad Prism5

Statistical analysis of in-vitro release of nanaogels (Pure Drug as PD and nanogels F1-F6) was performed by GraphPad Prism5 using One-way ANOVA by Dunniet.

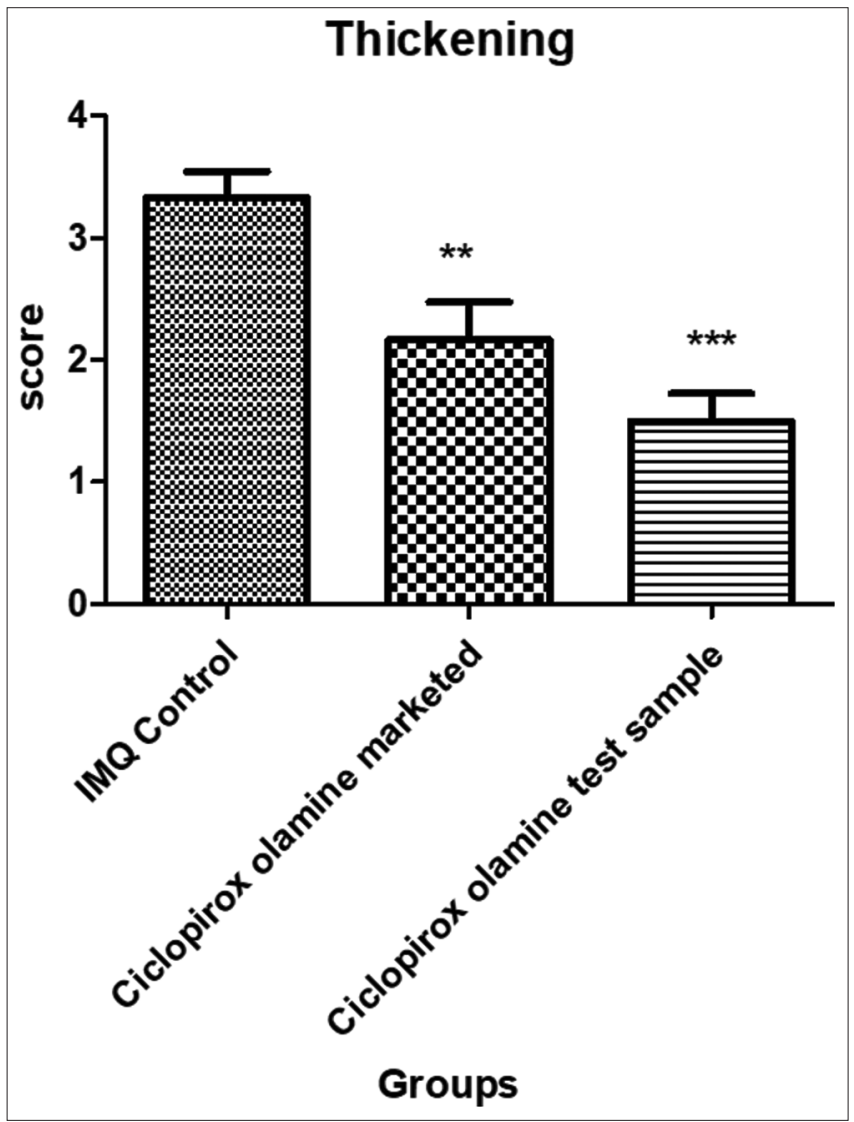

Fig. 18: Thickening dermatitis graph of antifungal nanogel-F6

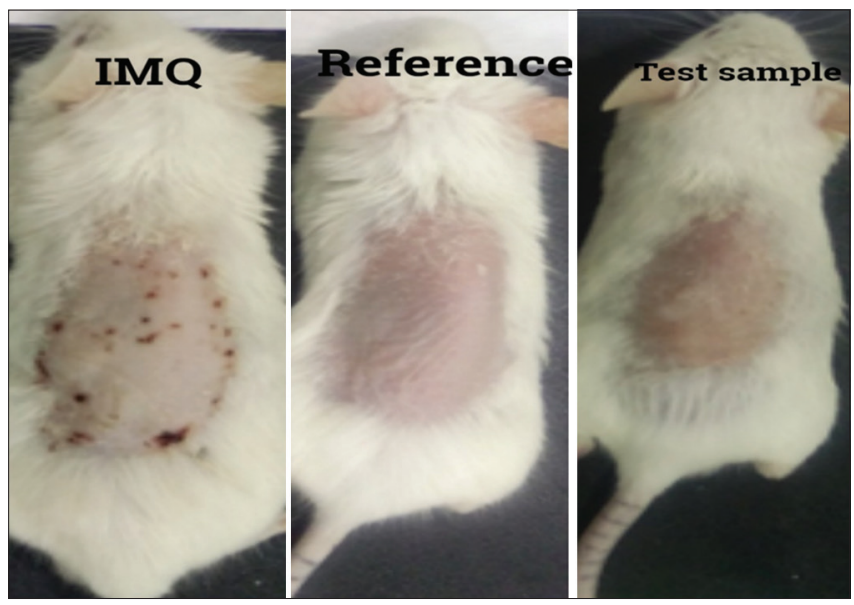

Fig. 19: In-vivo study-dermatitis model mice in Imiquimod (IMQ), reference and test sample (Nanogel formulation-F6)

In-vivo study of antifungal nanogel (F6)

Severity scoring of dermatitis

After the treatment period, the dermatitis was scored based on erythema, scaling and thickening were scored independently on a scale from 0 to 4 , Whereas 0 value indicates-none; 1 - slight; 2-moderate; 3-marked and 4-very marked (Figs. 16-19).

\section{CONCLUSION}

Ciclopirox olamine nanogel was formulated using homogenization technique. The release profiles of prepared naongels exhibited an 
inflection point which indicated nanogel formation on diffusion membrane in donor compartment of the diffusion cell. During nanogel formation, formulation got converted into the gel phase and drug release became slow. The result showed that effectively formulated stable antifungal nanogel encompassing ciclopirox olamine which would release drug for an extended period of time. Nangogel (F6) showed better local absorption with low systemic absorption of potentially toxic antifungal drug has verified to be promising approach for the treatment of actio mycosis. However, ciclopirox olamine test sample was found to be more potent than the marketed formulation because the dermatitis score was less in the test sample than the marketed formulation.

\section{ACKNOWLEDGMENT}

The authors are thankful to the management of KLE College of Pharmacy, Bengaluru for providing the necessary facilities to carry out the work.

\section{CONFLICTS OF INTEREST}

There are no conflicts of interest regarding the publication.

\section{AUTHORS CONTRIBUTIONS}

- All the authors contributed to the preparation of final manuscript.

- Anusuya Patil contributed in performing the experimental work

- Pranoti contributed in analyzing FT-IR spectra.

\section{AUTHORS FUNDING}

The authors did not receive any funding for this research work.

\section{REFERENCES}

1. Shah PP, Desai PR, Patel AR, Singh MS. Skin permeating nanogel for cutaneous co-delivery of the two anti-inflammatory drugs. Biomaterials 2012;33 Suppl 5:1607-17.

2. Kumar S, Talegaonker S, Negi LM, Khan ZI. Design and development of ciclopirox topical nanoemulsion Gel for the treatment of subungal onycomycosis. Indian J Pharm Educ Res 2012;46 Suppl 4:303-10.

3. Kamble A, Badde S, Kumar A, Pokharkar VB. Devlopment and characterzation of liposomal drug delivery system for nimesulide. Int J Pharm Pharm Sci 2010;2 Suupl 4:87-9.

4. Panonnummal R, Jayakumar R, Sabitha M. Comparative anti-psoriatic efficacy studies of clobetasol loaded chitin nanogel and marketed cream. Eur J Pharm Sci 2017;96:193-206.

5. Divya G, Panonnummal R, Gupta S, Jayakumara R, Sabitha M. Acitretin and Aloe-emodin loaded chitin nanogel for the treatment of psoriasis. Eur J Pham Biopharm 2016;107:97-109.
6. Singka GS, Samah NA, Zulfakar MH, Yurdasiper A, Heard CM. Eur J Pharm Biopharm 2010;76 Suppl 2:275-81.

7. Raphael AP, Garrastazu G, Sanvico F, Prow TW. Formulation design for topical drug and nanoparticle treatment of skin diseases. Ther Deliv 2015;6 Suppl 2:197-216.

8. Tomar S, Singhal T. Pre-formulation studies of niosomal gel of prednisolone and azithromycin for topical drug delivery system. J Innov Pharm Biol Sci 2015;2 Suppl 3:312-21.

9. Basha BN, Prakasam K, Goli D. Formulation and evaluation of gel containing fluconazole antifungal agent. Int J Drug Dev Res 2011;3 Suppl 4:109-28.

10. Elkomy MH, Elmenshawe SF, Eid MH, Ali AM. Topical ketoprofen nanogel: Artificial neural network optimization, clustered bootstrap validation, and in vivo activity evaluation based on longitudinal dose response modeling. Drug Deliv 2016;23 Suppl 6:3294-306.

11. Talele S, Nikam P, Ghosh B, Deore C, Jaybhave A, Jadhav A. A research article on nanogel as topical promising drug delivery for diclofenac sodium. Indian J Pharm Educ Res 2017;51 Suppl 4:530-6.

12. Sabir F, Asad MI, Qindee M, Afza I, Dar MJ, Shah KU, et al., Polymeric nanogel as versatile nano platforms for biomedical applications. J Nanomater. 2019;20 Suppl 2:1155-71.

13. Amir M, Khatoon F. Different type of smart nanogel for targated delivery. J Sci 2019;4 Supp1 2:201-12.

14. Ramadon AE, Ramadon D, Harmita. Formulation and evaluation of gel and emulgel of chili extract (Capsicum frutescens L.) as topical dosage forms. Int J Pharm Pharm Sci 2014;6 Suppl 3:13-6.

15. Myuri E, Veglianese P, Papa S, Mariani A, De Paola M, Rigamonti R, et al. Double conjugated nanogel for selective intracullar drug delivery. RSC Adv 2017;48 Suppl 19:456-65.

16. Toprakcioglu Z, Challa PK, Morse DB, Knowles T. Attoliter protein nanogel from droplet nanofluidics for intracullar delivery. Sci Adv 2020;6 Suppl 6:7952-77

17. Agrawal S, Karar PK, Agarwal G. Formulation and evaluation of semi-herbal nanogel of clindamycin phosphate and Aloe vera. 2017;2 Suppl 5:2111-23.

18. Ni J, Wang D, Wang S. Meta analysis of randomized controlled trials of podophyllotoxin nanogel in treatment of Condyloma acuminatum. 2019;12 Suppl 11:12647-57

19. Ji P, Zhang W, Ai S, Zhang Y, Liu J, Liu J, et al. Hybridization of graphene oxide into nanogels to acquire higher photothermal effects for therapeutic delivery. Nanotechnology 2019;30 Suppl 11:29906-34.

20. Messi L, Najer A, Chapman R, Spicer CD, Nele V, Che J, et al. Tuneable peptide cross linked nanogel for enzyme triggered protein delivery. J Mater Chem B 2020;45 Suppl 32:55678-89.

21. Look M, Stern E, Wang QA, DiPlacido LD, Kashgarian M, Craft J, et al. Nanogel based on delivery of mychophenolic acid ameliorates systemic lupus erythromatosis in mice. J Clin Invest 2013;123:1741-9.

22. Tran TV, Phuong TH, Tran NQ, Nguyen CK, Nguyen DH. Polymeric chitosan based nanogels as a potential platform for dual targeted drug delivery in cancer therapy. Int J Nanotechnol 2018;15 Suppl 3:188-98. 